\title{
Implementation of an ergonomics program for the welding department inside a car assembly company
}

\author{
Caceres Francisco and Troya Edwin ${ }^{\mathrm{a}}$ \\ ${ }^{a}$ School of Communication, Universidad de Las Americas , Granados Av. E12-41 Colimes Street , Quito - \\ Ecuador, South America .
}

\begin{abstract}
The premise for this project is to implement an ergonomics program for the welding department of a car assembly company, considering that this area represents the highest occupational risk in relation to musculoskeletal injuries. The project also allows the demonstration of the different implementation processes of an ergonomics program; it also permits the determination of individual risks faced by workers of the welding department, and finally gives a chance of improving common injuries using the sentinel system. The main challenge is to reduce musculoskeletal injuries and absenteeism among welders through actions implemented by the ergonomics program.
\end{abstract}

Keywords: ergonomics, welding staff, car assembly company, musculoskeletal injuries.

\section{Introduction}

The Ecuadorian car assembly company is located in Quito, Ecuador; this company is specialized in vehicle assembly and distribution, and has an installed capacity of 9,000 units per year. Car Assembly Company Quality Manual (2007)

Within the production process, the cabs welding area is the place where metal parts are welded using electric spot welders. In this quarter several contact risks may occur such as: electric shock, chemical hazards, exposure to welding fumes and ergonomics hazards; this last risk is the result of inadequate postures during operation, and repetitive movements while operating welders. Rothwell et al (2009)

It is important to emphasize that many welding injuries may occur due to low levels of automation processes and the need of constant physical effort from the operators. Most of the tasks and procedures welders must comply require a variety of movements (bending, stretching and standing for long periods of time) that oblige them to move constantly.

In similar car assembly companies, welding processes have been automated and are performed by computerized machines and not by men. In some
* welding processes welders actively participate in the execution of these tasks; while performing the mentioned duties a welder must use specific muscle groups (lumbar muscles, shoulder girdle) resulting in overload and increase the risk of injuries. Velez et al (2008)

There is very little international information related to this subject, especially since this type of risk has been eliminated by automation of welding processes in the automobile industry throughout developed countries, but still remains in car assembly companies located in developing countries.

Absenteeism inside the welding department is one of the highest in the company because of musculoskeletal injuries. HR Report 2008 , this elevated absenteeism tendency is related to the need of performing some tasks that involve non-adapted inadequate postures, repetitive movements, standing for long periods of time, lifting heavy weight and the use of tools.

There are three high-risk activities in welding cabs: Transportation of the cab's roof, welding of the

\footnotetext{
*Corresponding author e-mail: fcaceres@mazda.ec
} 
bed's floor, and welding of the cab's roof. Process Manual (Revised 2008)

The Company's Health and Safety Department has given priority to examine and study medical problems that often occur among workers and that usually lead to greater absenteeism. The statistics obtained from this department analysis have identified the cabs welding area as the quarter with most absenteeism due to musculoskeletal injuries. Company's Morbidity Report HR 2008.

Given this reality, the company promoted an Individual Ergonomics Risk Assessment throughout the Evaluation of Postures and Baropodometry, which is the study of the shape, size and pressure of the worker's feet. This study will allow us to have individual and unique quantitative results that will help prevent future musculoskeletal injuries among cabs welding personnel, plus the implementation of a Lumbar Spine School - Active breaks, stretching exercises and ergonomic improvements.

Objectives to demonstrate the different processes of the ergonomics program implementation, determine individual risk profiles, identify most common injuries through the sentinel system, Reduce musculoskeletal injuries and absenteeism among welders through actions implemented by the ergonomics team.

\section{Methods}

The cabs welding personnel was evaluated under the following parameters: individual ergonomics risk assessment: direct observation of the workers, basic daily activities and activities of daily living, posturography, foot analysis, Schober test (spine flexibility test), chains test (biocinematics chain),fukuda test, photographs (body and feet postures)

Baropodometry Evaluation : This new technology involves a complete foot analysis, with help from an electronic machine that delivers accurate and reliable information regarding human feet. With this machine we can understand shapes, dimensions, and different pressures that welders put on their feet while performing different tasks.

Technical Equipment Used: Baropodometry Foot Scanner: the evaluations performed on each one of the welding staff members were done with help from an electronic pressure detector platform.

The foot scanner employed in this evaluation has a torque platform of $65 \mathrm{~cm}$. x $63 \mathrm{~cm}$. This machine also has 9800 sensors, which are flexible and have a diameter of one tenth of a millimeter, a resolution of
2.4 sensors per $\mathrm{cm} 2$, a pressure range between 0.1 PSI (Pounds per Square Inch) this pressure can exert a force of 1 Newton over an area of $1 \mathrm{~m} 2$. Finally this scanner has a monitoring capacity of $120 \mathrm{~Hz}$ which allows the measurement of pressure changes that may occur while an individual is stepping, standing, or walking on the platform. All this data is forwarded and stored inside the computer every single time an individual moves out of his/her gravity center.

The Foot Scanner software receives and analyzes all the compiled records and processes it by comparing this data with normal standards for each age range, height and weight.

Measurements : Pressure exerted on the welder's feet soles: forefoot, midfoot and rearfoot. Welder's stability limits: changes found in each subject when they move out of their gravity center due to different actions backwards, forwards, sideways. Studies performed while welders walk through the platform: width, length, symmetry between steps. Balance Control with their eyes open.

Lumbar Spine School - Active Stretching Breaks.

The Lumbar Spine School program was designed as a workshop to provide safety and health tools for all employees performing any kind of physical labor. This program provides information about mechanical and psychosocial factors involving the Lumbar Spine (detail information is offered like how the lumbar spine works and what purpose it has inside the human body, postural Hygiene, Ergonomics, and how to manually lift heavy weight). Every meeting is two hours long and it is offered inside the company's training facility.

The Active Break Program is a sequence of compensatory stretching, breathing and strengthening exercises performed at the beginning of the day. This program is executed by every single welder three days a week for 10 minutes long. This routine offers exercises for the neck, arms, back and legs and it involves flexion, extension and rotation movements.

Ergonomic Improvements : Staff, Customized hydration program for the welding department personnel, according to individual assessment. (height, weight).

Hydrokinesitherapy treatments according to clinical evaluation results from individually damaged muscle chains.

Modification of personal protective gear (uniforms): While at work welders are required to wear pants made of fabric 70 grams thick, they must also put on $100 \%$ cotton t-shirts or polos. In order to better protect the chest and arms the company has decided to design an extra accessory to the uniform 
made out of cowhide, for ventilation purposes and reduction of overheating. In the back of this accessory exists an opening that helps eliminate heat and increases sweat elimination.

Workstation - Placing Trolys: (simple fulcrum equipment that helps reducing the weight of the electric spot welder on the person using it) creates a support for welding hoses, reducing weight pressure on the welder while performing his job.

Beams Separation: Mechanically this design allows a beam to be next to the transformer and the other one to be free, that way the welder can have more freedom of movement and decreased the physical effort during the transportation of welds to the cabs.

Placement of a circular support for the electric spot welder - a circular support was implemented on the electric spot welder handlebars, in order to facilitate the manual movement of the tool.

Placement of a rail extension for a greater movement of the troly - this rail extension increases the electric spot welder reach, preventing unnecessary effort from the worker's muscular girdle.

\section{Results}

Most of the personnel inside the welding department are between the ages of twenty and thirty years old but there are two welders that are over forty.

Most of the welding department staff is relatively new and nearly every single one of them will remain in this department less than five years, it is important to highlight that injury risks have increased due to the existence of operational staff who had been working in the same welding station for more than twenty years.

The welding department ranks second in absenteeism due to medical reasons. The highest absenteeism is given outside of the workplace at hospital care facilities. This tendency is directly reflected in the operational cost.

The individual ergonomics risk evaluation was performed using three different tests: Posturography, Foot Analysis, and Schober's test. All the results obtained from this tests, were distributed in four different levels each one assigned with a color according to the intensity of risk found on a subject. Risks levels : very good / good / regular / low / null

The posture evaluation among welders was mostly very good. The results obtained from the Schober's test were classified inside the very good level, mean- ing that the welding department workers have an adequate flexibility (Level 1). It is important to highlight that two of the welders obtained a low level of flexibility (Level 4).

The prevalent Foot shape among this group is the Roman foot shape. The analysis performed on the welder's feet showed a medium to low level of risk on their feet ..

Pathologies Found : number of subjects, lower limbs pathologies, biomechanical alterations, lower limbs asymmetry, pain and foot discomfort, balance disorders, toes to not help in support, cross footprint, overweight, excess of pressure over metatarsal.

\section{Discussion}

The Welding tools (electric spot welders) adapted from previous assembly lines still maintain their original assembly standards even though at this time the cars that have been built with them have changed.

At the moment these welding tools cannot be replaced due to the fact that it will represent an elevated and direct cost for the company. Due to this lack of new and adequate tools the company workers must "find a way around it". The cars manufactured have changed with time but the tools that put them together have not. Some adaptations have been made in order to create a quality final product but at the end the workers operating the machines have to sacrifice comfort and sometimes their own health.

Welders that need to be standing for long periods of time were injured in a greater extent compared to other workers inside the company. Welders must remain standing while welding cabs, pulling hoses, welding top parts, welding the back of seats, welding roofs and windshields.

It seems that the long hours standing during a workday, provoke a number of podiatric disorders related to the increase of pressure especially in the worker's rearfoot. The tests run on the subjects showed results of $64.7 \%$ of individuals suffering from this disorder.

The alterations found in the plantar pressure diversion, are reflected in an excess of pressure in the back of the foot, this results were recorded in red color by the Baropodometry and the obtained results range from $52 \%$ to $92 \%$.

The hyper-pressure at different areas of the foot, caused either by previous patient pathology, standing for long periods of time, or wearing inadequate shoes 
has caused the greatest number of podalgia, edemas, and keratosis.

Knowing that $58.8 \%$ of the welders inside the company have a Roman type foot it would be extremely important to choose an adequate shoe for this kind of feet taking into consideration not only the shape, but also the size and appropriate safe guards.

In addition to all the above, we believe that it is extremely important to implement a proper podiatric treatment among all welders. (Providing orthopedic insoles for each one of the welders) To reduce injuries among welders, they must wear adequate footwear during working hours and outside of work.

From an injury prevention perspective, the company should provide welders with orthotic insoles, toe separators, and full and partial spikes. In this environment, the advantage is that using a set of objective foot measures, the worker and those responsible for gear acquisition can know a shoe that is going to provide a better fit and will be more comfortable.

In summary, the features incorporated in this new research methodology allows the purchase of products that best meet the demands of workers who increasingly require higher standard gear that offers them comfort and safety.

Work Footwear: Safety Boots

The safety steel toe boots, posture control insoles, heelpieces, metatarsal pads, toe separators, and orthotic gear must be: firm, flexible, and comfortable while providing protection for the workers feet.

Lumbar Spine School

Lower back pain is commonly found among all operating personnel inside the assembly company, but it occurs in greater frequency among cabs welders.

Therefore, it is necessary that all workers follow a program that emphasizes a preventive way of living. This program educates the workers on how to have a better quality life that will help them prevent musculoskeletal injuries and reduce back pain. In order to accomplish this program the company created the Lumbar Spine School as an obligatory responsibility among all workers.

Since the lifting biomechanical training was a success all lumbar belts are no longer required among welders. Workers now understand and comply with all lifting procedures that will help them prevent any injuries while manually lifting heavy weights.

Through this program all welders acquired skills in how to perform their jobs in a responsible way working practicing good posture and following active stretching breaks.
Recommendations: Replace welding tools according to different types of cars and trucks to be assembled, taking into account workers anthropometric and work scope. Implement circulatory exercises for relaxation among workers that need to remain standing for long periods of time. Suggest to the purchasing department to purchase equipment, accessories and security boots based on the results obtained from baropodometry and posture evaluation. Enforce that all area supervisors control the execution of body mechanics learned at the Lumbar Spine School. Establish an incentive program based on accomplishments and job performance among welders.

\section{References}

[1] M.K. Vélez, Posturology Clinic. Body Balance and Health , Ed. Universidad de las Américas. Quito Ecuador 2011

[2] M. Vélez, Physiotherapy Systems - Methods - Techniques, Ed. Sur Editores. Quito Ecuador 1997.

[3] C. Gallozi, Posture Department of Physiology and Biomechanics, E. CONI. Italy.2003

[4] P Viladot, Clinical and Treatment of Diseases of the feet, Ed. Científica Médica. Barcelona 1.959

[5] B. Bricot, Riprogrammazione posturale globale, Ed. Sauramps Medical ,1996.

[6] Ecuadorian Car Assembly Company. Quality Manual ISO 9001. Seventh Revision. 2008

[7] Ecuadorian Car Assembly Company. Cabs Welding Processes Manual. Fifth Version. 2007

[8] L. Lisandro, Posturología e Oculística. Ospedale Pediatrico "G. Di Cristina" - Palermo-Unità Operativa di Oculistica 2002

[9] MR..Jouvencel, Basic Ergonomics applied to the Occupational Medicine. Ed. Díaz de Santos. Madrid. 1994.

[10] OSHA Guidelines for Shipyards; OSHA 3341-03N (2008) Ergonomics for the prevention of Musculoskeletal Disorders http://www.osha.gov/dsg/guidance/shipyard-guidelines.html

[11]National Institute for Occupational Safety and Health: Publication number 2007- 131: Ergonomics Guidelines for Manual Material Handling http://www.cdc.gov/niosh/docs/2007-131/.

[12]Department of Defense Instruction Safety and Occupation Health Program (DoDI) 6055.1, Enclosure (6) DoD Ergonomic Program Requirements and Procedures, http://www.dtic.mil/whs/directives/corres/pdf/605501p.pdf 